\title{
SISTEM PEMANTAUAN KETINGGIAN AIR DAN CURAH HUJAN SERTA KONTROL PINTU AIR PADA SIMULASI BENDUNGAN BERBASIS IOT DENGAN HMI SCADA
}

\author{
Hilal Quthbirrobbaani ${ }^{1}$ \\ Program Studi D-III Teknik Elektronika Politeknik Negeri Bandung \\ Email: hilalquthbirrobbaani@gmail.com \\ Suyanto ${ }^{1}$ \\ Program Studi D-III Teknik Elektronika Politeknik Negeri Bandung \\ Email: suyanto@polban.ac.id \\ Endang Sukarna ${ }^{1}$ \\ Program Studi D-III Teknik Elektronika Politeknik Negeri Bandung \\ Email: endang_sukarna2000@yahoo.co.uk
}

\begin{abstract}
S : Dams are structures that play a critical role in flood management. A water level meter and a floodgate control are installed on the dam to enable this function. With the limited actions performed by the duty officers, manual water level measurement cannot be done on a continual basis. Furthermore, physically opening and closing the sluice gate requires human effort. The subject of this final research project is on making tools for monitoring water levels and rainfall continuously and in real time remotely, as well as designing systems that can control sluice gates automatically or manually by operators remotely. From the test results, the duration of the sensor data transmission is 1,21 seconds, with an error value of 2,97\% of the air altitude sensor reading of the actual value and the rainfall sensor value of 0,053 inches/trip.. In addition, the duration of sending the sluice gate opening/closing instruction is 0,84 seconds and has a precision level of $100 \%$ of sluice gate. Sluice control settings can use automatic or manual control modes. Data from sensor readings and sluice control are contained in the SCADA HMI, which can be monitored and controlled remotely with IoT communicated.

Keywords: Dam, Water level sensor, Sluice control, IoT, HMI SCADA
\end{abstract}

ABSTRAK: Bendungan merupakan bangunan yang memiliki peran penting dalam pengendalian banjir. Untuk dapat melakukan fungsi tersebut, terdapat pengukur ketinggian muka air serta kontrol pintu air pada bendungan. Pengukuran ketinggian muka air secara manual tidak bisa dilakukan secara terus menerus dengan keterbatasan kegiatan yang dilakukan petugas jaga. Dan juga, pengaturan pintu air secara manual masih menggunakan tenaga manusia. Penelitian tugas akhir ini berfokus pada pembuatan alat untuk pemantauan ketinggian air dan curah hujan secara terus-menerus dari jarak jauh, serta merancang sistem yang dapat mengontrol pintu air secara otomatis maupun manual oleh operator dari jarak jauh selama terdapat jaringan internet dengan komunikasi IoT. Dari hasil pengujian menunjukkan bahwa durasi pengiriman data sensor terhitung sebesar 1,21 detik, dengan nilai persentase error pembacaan sensor ketinggian air sebesar 2,97\% dari nilai ketinggian air sebenarnya dan nilai sensor curah hujan sebesar 0,053 inch/trip. Selain itu, untuk durasi pengiriman instruksi buka/tutup pintu air terhitung sebesar 0,84 detik dan memiliki tingkat presisi bukaan pintu air sebesar 100. Pengaturan kontrol pintu air dapat menggunakan mode kontrol otomatis maupun manual. Data hasil pembacaan sensor maupun kontrol pintu air terdapat pada HMI SCADA, yang dapat dipantau dan dikontrol dari jarak jauh.

Kata Kunci: Bendungan, Sensor ketinggian air, Kontrol pintu air, IoT, HMI SCADA

\section{PENDAHULUAN}

$\mathrm{B}$ endungan merupakan bangunan yang berperan dalam meminimalisir terjadinya banjir, terutama di daerah yang lebih rendah dari bendungan. Bendungan sendiri memiliki fungsi dalam menampung air, dan dari air yang terbendung tersebut terbentuklah waduk. Pada bendungan, terutama yang memiliki fungsi utama sebagai pengendali banjir, terdapat pintu air untuk mengontrol debit air yang mengalir ke daerah yang lebih rendah agar dapat meminimalisir terjadinya banjir dan juga untuk mengontrol ketinggian muka air pada bendungan itu sendiri, agar tidak terjadi luapan air yang dapat mengakibatkan banjir di daerah sekitar bendungan.

Bendungan, secara sederhana terdapat pengukur ketinggian air konvensional yang biasanya menggunakan mistar, dan juga terdapat kontrol pintu air yang sebagian masih dioperasikan dengan cara manual menggunakan tenaga manusia. Komponen tersebut merupakan salah satu hal penting pada operasi bendungan, di mana pengukur ketinggian memberikan informasi terkait kondisi tinggi muka air pada bendungan. Dari kondisi yang telah diketahui, ditentukan kapan pintu air dibuka dan ditutup. Masih manualnya operasi dan pemantauan yang dilakukan, tidak menutup kemungkinan adanya kesalahan dan keterlambatan dalam pemberian informasi serta aksi pada operasi pengaturan pintu air. Adanya suatu sistem baru untuk pemantauan dan kontrol pada bendungan, yang dapat meminimalkan hal tersebut akan sangat membantu

\footnotetext{
${ }^{1}$ Program Studi D-III Teknik Elektronika Politeknik Negeri Bandung
} 
dalam penanganan banjir.

Pada bendungan selain pemantauan tinggi muka air, terdapat juga pemantauan curah air hujan sebagai informasi tambahan terhadap kondisi cuaca didaerah sekitar bendungan atau daerah sekitar aliran sungai yang mengarah ke bendungan.

Adanya sistem baru yang dapat mengintegrasikan itu semua diharapkan dapat menjadi kemudahan dalam melakukan pemantauan tinggi muka air dan curah hujan secara otomatis, maupun dalam melakukan kontrol pintu air, terlebih lagi semuanya dapat dilakukan dari jarak jauh.

\section{Bendungan}

\section{KAJIAN PUSTAKA}

Bendungan menurut Menteri PUPR Nomor 27/PRT/M/2015 tentang Bendungan mendefinisikan bendungan merupakan bangunan yang berupa urukan tanah, urukan batu, dan beton, yang dibangun selain sebagai penahan serta penampung air, dapat juga dibangun sebagai penahan dan penampung limbah rambang, maupun penampung lumpur sehingga terbentuk waduk. Setelah terbentuk waduk, bendungan mempunyai peran dan manfaat salah satunya sebagai penyimpan air dan pengendalian banjir [1] . Pada bendungan terdapat beberapa komponen pembentuk, yaitu [2]:

1. Badan bendungan

2. Pondasi

3. Pintu air

4. Bangunan pelimpah

5. Kanal

6. Reservoir

7. Stilling basin

8. Katup

9. Drainage gallery

\section{SCADA}

SCADA merupakan kependekan dari Supervisory Control and Data Acquisition adalah sistem pengontrolan serta akuisisi data yang umumnya digunakan pada lingkungan industri untuk memonitoring serta mengendalikan peralatan yang terdapat pada plant dan menampilkan data pengukuran plant pada HMI [3] . SCADA umumnya terdiri dari beberapa RTU yang memiliki fungsi dalam mengumpulkan data dan mengirimkan ke master station menggunakan sistem komunikasi tertentu [4]. Pada umumnya sistem SCADA mempunyai 4 unsur utama, yaitu [3]:

1. Master Terminal Unit (MTU)

2. Remote Terminal Unit (RTU)

3. Sistem Komunikasi

4. SCADA Software

Berikut merupakan arsitektur SCADA secara umum.

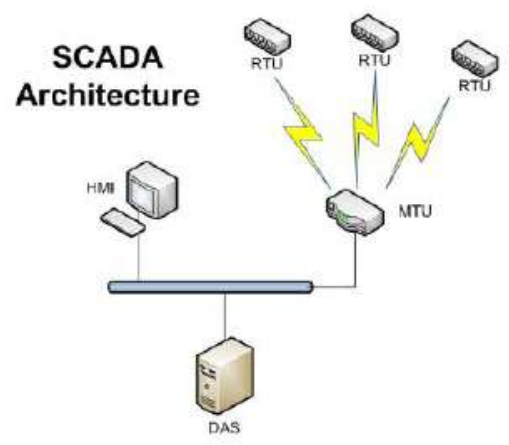

Gambar 1. Arsitektur SCADA [5]

\section{Internet of Things}

Dalam buku "Pengantar Teknologi Internet of Things(IoT)", IoT atau Internet of Things sudah diperkenalkan dari tahun 1999 oleh Kevin Ashton yang merupakan co-founder Auto-IDE Lab MIT. Menurut 
Kevin Ashton IoT merupakan sensor-sensor yang terhubung ke internet dan berperilaku seperti internet dengan membuat koneksi-koneksi terbuka setiap saat, serta berbagi data secara bebas dan memungkinkan aplikasiaplikasi yang tidak terduga, sehingga komputer-komputer dapat memahami dunia di sekitar mereka dan menjadi bagian dari kehidupan manusia [6].

Terdapat 7 layer untuk memahami sebuah IoT, yaitu [6]:

1. Physical devices and controller

2. Connectivity

3. Edge computing

4. Data accumulation

5. Data abstraction

6. Application

7. Collaboration and process

\section{MQTT}

MQTT adalah protokol komunikasi machine to machine (M2M) dan IoT. MQTT adalah protokol pengiriman pesan yang ringan berbasis broker dengan mekanisme "publish/subscribe" dan bekerja di atas protokol TCP/IP. Diagram di bawah ini menunjukkan protokol MQTT di atas TCP/IP [7].

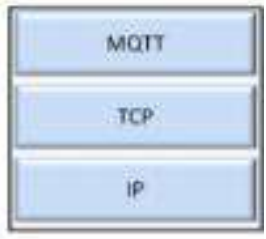

Gambar 2. Diagram Prokotol Komunikasi [7]

Protokol MQTT memiliki konsep berbeda dengan protokol lain seperti HTTP yang menggunakan konsep request/response. Konsep yang digunakan pada protokol MQTT adalah publish/subscribe. Pusat komunikasi utama pada MQTT adalah MQTT broker yang bertanggung jawab untuk mengirim semua pesan diantara pengirim dan penerima yang sah [8].

Setiap client yang mengirim pesan ke broker harus menyisipkan informasi nama topik yang dituju. Topik adalah informasi routing untuk broker yang bertugas mengarahkan pesan yang masuk ke dala broker. Client yang ingin menerima pesan harus melakukan subcscribe ke topik yang dituju dan selanjutnya broker akan mengirimkan semua pesan yang diarahkan pada topik tersebut. Oleh karena itu, client tidak perlu saling mengenal, mereka dapat berkomunikasi melalui topik ini [8].

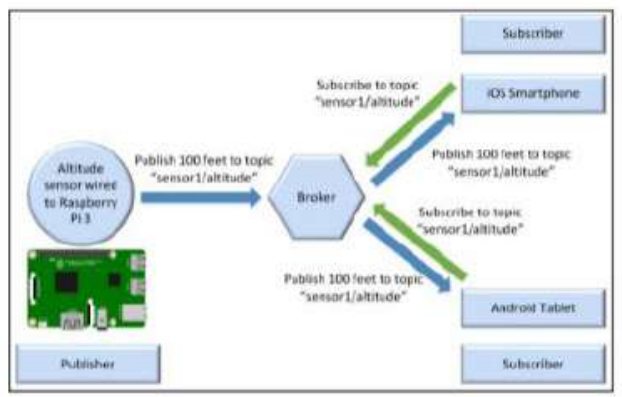

— Gambar 3. Alur Komunikasi Prokotol MQTT [8]

\section{Motor Stepper}

Motor memiliki beberapa jenis yang umum digunakan, seperti halnya motor stepper. Motor stepper memiliki rotor dan stator, dimana rotor merupakan poros berputar dan stator merupakan elektromagnet stasioner di sekitar rotor [9].

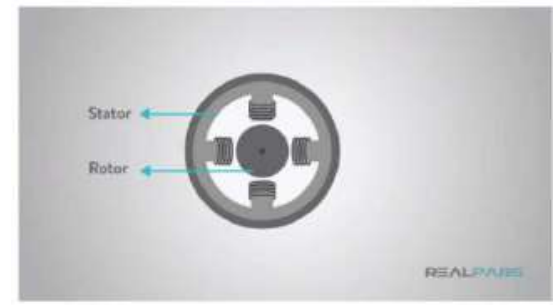

Gambar 4. Sketsa Rotor dan Stator pada Motor Stepper [9] 
Motor stepper bergerak dengan mengkonversi pulsa elektronis menjadi gerakan mekanis diskrit. Pergerakan motor stepper itu sendiri ditentukan oleh urutan pulsa yang diberikan. Motor stepper dapat diatur putarannya dengan bantuan driver. Setiap pulsa merepresentasikan step dari motor stepper, dengan 1 step merupakan pergerakan motor stepper sesuai perubahan sudut tiap 1 step. Perubahan sudut per satu step berbedabeda sesuai dengan spesifikasi motor stepper yang digunakan. [10]

\section{Water Level Sensor}

Water Level Sensor atau Sensor Ketinggian Air adalah sensor yang dapat mendeteksi ketinggian cairan pada suatu wadah [11]. Salah satu jenis sensornya adalah sensor ultrasonik, dimana sensor ultrasonik sendiri merupakan sensor yang memiliki fungsi mengubah besaran fisis atau bunyi menjadi besaran listrik dan begitu pulsa sebaliknya. Untuk sensor ultrasonik, bekerja dengan memancarkan dan menerima gelombang ultrasonik. Waktu yang diperlukan gelombang untuk menatul kembali adalah bagaimana jarak diukur. Gelombang ultrasonik memiliki frekuensi yang sangat tinggi dan mencapai $20.000 \mathrm{~Hz}$, frekuensi ini tidak dapat didengar oleh manusia dan hanya dapat didengar oleh hewan tertentu seperti kucing, anjing, kelelawar dan lumba-lumba [12].

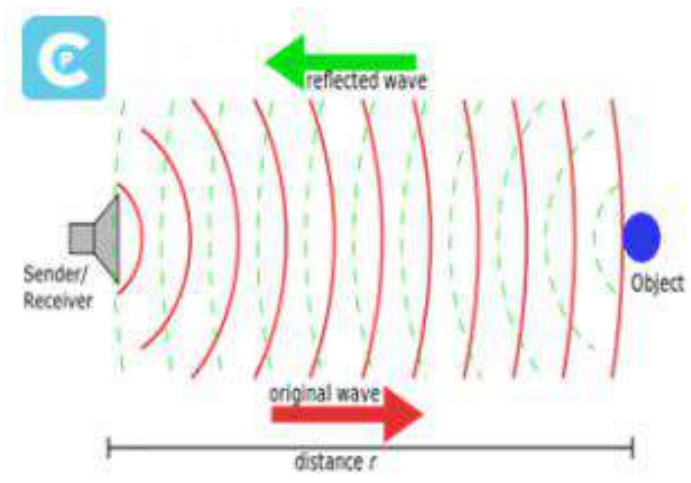

Gambar 5. Ilustrasi Cara Kerja Sensor Ultrasonik [12]

\section{METODOLOGI PENELITIAN}

\section{Diagram Blok dan Cara Kerja Sistem}

Berikut merupakan diagram blok dari sistem.

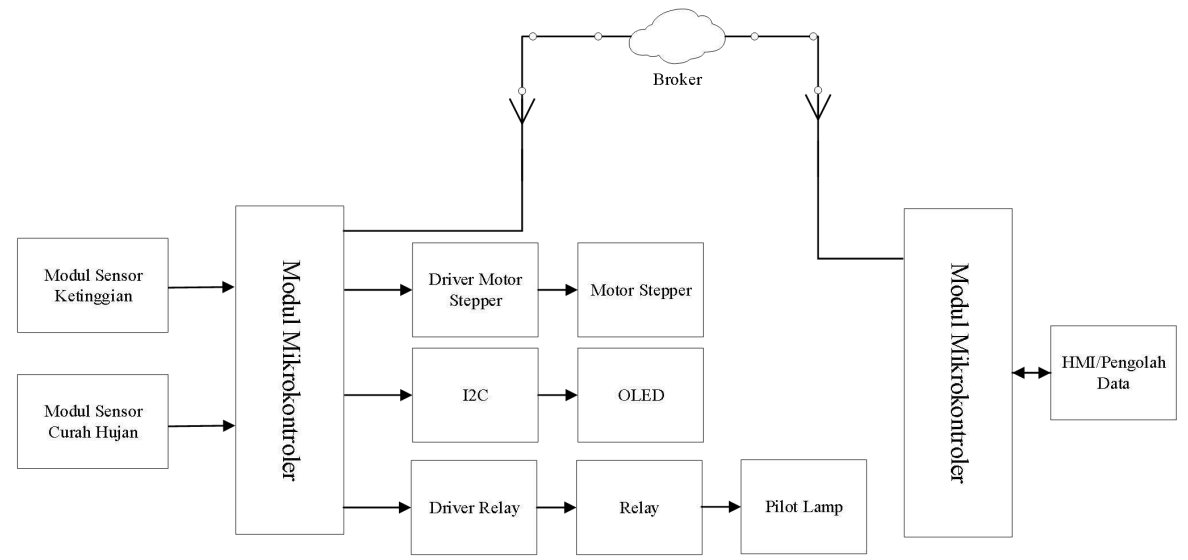

Gambar 6. Diagram Blok Sistem

Cara kerja dari sistem yang akan dibuat adalah pada plant akan terdapat sensor untuk mendeteksi ketinggian air dan curah hujan, serta aktuator berupa motor stepper yang akan menggerakkan pintu air, dengan menggunakan konsep IoT dalam sistem komunikasinya. Sensor ketinggian air dan sensor curah hujan akan terhubung dengan modul mikrokontroler, dimana hasil pengukuran akan diproses terlebih dahulu oleh modul mikrokontroler yang kemudian akan dikirim ke modul mikrokontroler yang terhubung dengan HMI SCADA melalui jaringan internet dan perantara MQTT Broker. Hasil pembacaan tersebut akan ditampilkan pada HMI SCADA dengan menggunakan protokol OPC untuk menghubungkan antara HMI SCADA dengan modul 
mikrokontroler. Data yang tertampil pada HMI SCADA akan memberikan informasi kapan pintu air dibuka dan ditutup dengan alarm yang disetting dalam 3 mode, yaitu siap, siaga, dan awas dengan menggunakan jenis alarm value. Alur antara HMI dan motor stepper merupakan kebalikan dari pembacaan sensor, dimana motor stepper akan bergerak saat diberi perintah melalui HMI. Untuk plant yang digunakan sendiri merupakan miniatur bendungan, yang dapat mensimulasikan atau memvisualisasikan cara kerja bendungan dengan sederhana, yaitu dapat menampung air dan mengalirkannya melalui pengaturan pintu air, serta pengisian air akan dibantu menggunakan pompa.

Untuk curah hujan sendiri akan menggunakan cara manual dengan menjatuhkan air secara langsung pada sensor curah hujan. Air yang jatuh akan masuk ke tipping bucket, dimana tipping bucket merupakan 2 buah penampung air yang memiliki poros seperti jungkat-jungkat. Saat air pada satu sisi sudah penuh, maka sisi tersebut akan mengosongkan airnya dan pergerakan tersebut mengaktifkan switch yang akan menjadi clock pada modul mikrokontroler. Clock tersebut akan memberikan counter dan dikalikan dengan hasil kalibrasi tipping bucket yang merupakan banyaknya air yang menyebabkan tipping bucket bergerak. Nilai curah hujan yang tertampil pada HMI SCADA merupakan hasil kali antara jumlah counter dengan nilai kalibrasi tipping bucket. Hasil perkalian tersebut merupakan representasi dari nilai curah hujan dalam satuan inch atau mm.

\section{Spesifikasi Sistem}

Berikut merupakan spesifikasi umum dari sistem yang akan dibuat.

Tabel 1. Spesifikasi Sistem

\begin{tabular}{cll}
\hline No & \multicolumn{1}{c}{ Parameter } & \multicolumn{1}{c}{ Spesifikasi } \\
\hline 1 & Sumber Daya & $12 \mathrm{~V} / 3 \mathrm{~A}$ \\
2 & $\begin{array}{l}\text { Range pendeteksian } \\
\text { sensor ketinggian }\end{array}$ & $20-50 \mathrm{~cm}$ \\
\hline 3 & $\begin{array}{l}\text { Range pendeteksian } \\
\text { sensor curah hujan }\end{array}$ & $0-1000 \mathrm{~mm}$ \\
\hline 4 & Putaran motor stepper & Minimal 200 step/revolution \\
\hline 5 & Pin I/O mikrokontroler & Minimal 14 pin $(8$ pin digital, 4 pin analog output, 2 pin analog input $)$ \\
\hline 6 & $\begin{array}{l}\text { Ketersediaan wifi pada } \\
\text { mikrokontroler }\end{array}$ & Built in wifi $2.4 \mathrm{GHz}$ \\
\hline 7 & Dimensi box panel & $30 \mathrm{~cm} \times 20 \mathrm{~cm} \times 40 \mathrm{~cm}$ \\
\hline 8 & Dimensi plant & $100 \mathrm{~cm} \times 40 \mathrm{~cm} \times 30 \mathrm{~cm}$ \\
\hline 9 & Ketinggian air & $0-15 \mathrm{~cm}$ \\
\hline 10 & Jenis alam SCADA & Alam value \\
\hline 11 & Mode peringatan & 3 mode peringatan (siap, siaga, awas) \\
\hline 12 & Jenis komunikasi & Komunikasi IoT \\
\hline
\end{tabular}

\section{Perancangan dan Realisasi Mekanik}

Perancangan mekanik ini terdiri dari purwarupa dari bendungan, yang terdapat 2 komponen utama, yaitu penampung air dan juga pintu air, serta perancangan box panel elektronik. Dimensi dari purwarupa bendungan adalah $100 \mathrm{~cm}$ x $40 \mathrm{~cm}$ x $30 \mathrm{~cm}$, dan dimensi box panel adalah $30 \mathrm{~cm}$ x $20 \mathrm{~cm}$ x $40 \mathrm{~cm}$. Purwarupa bendungan akan dibuat dari mayoritas bahan akrilik denngan tebal $2 \mathrm{~mm}$, dan $3 \mathrm{~d}$ printing sebagai tambahan. Untuk box panel elektronik terbuat dari bahan plat besi dengan tebal $1 \mathrm{~mm}$. 


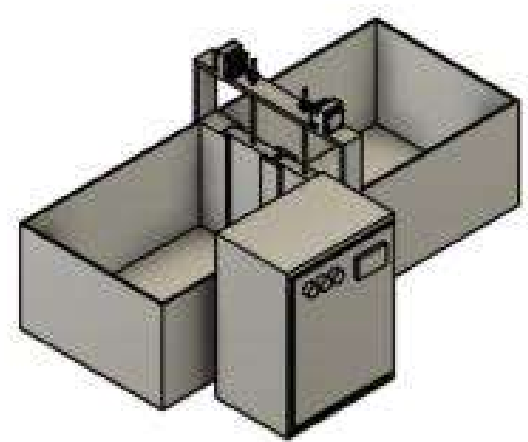

Gambar 7. Desain Mekanik

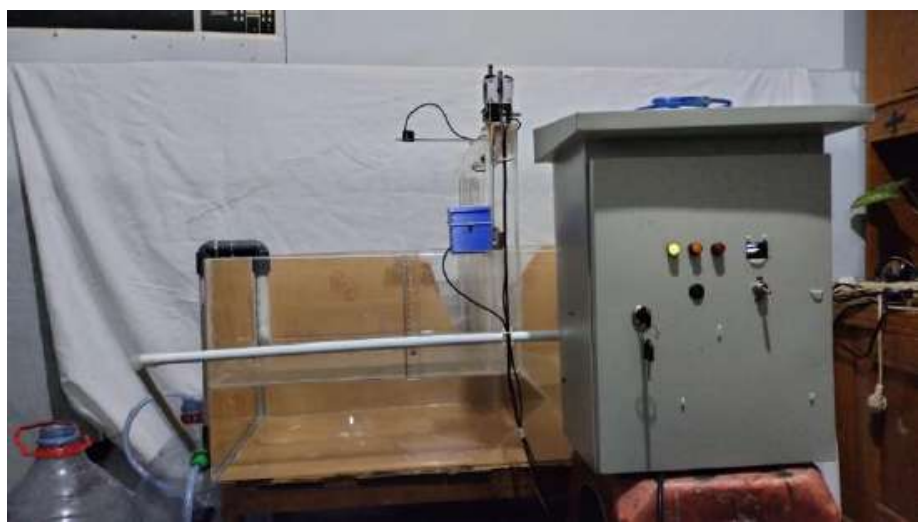

Gambar 8. Realisasi Mekanik Keseluruhan

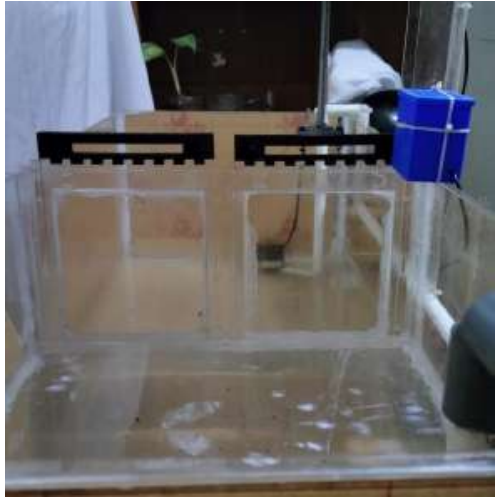

(a)

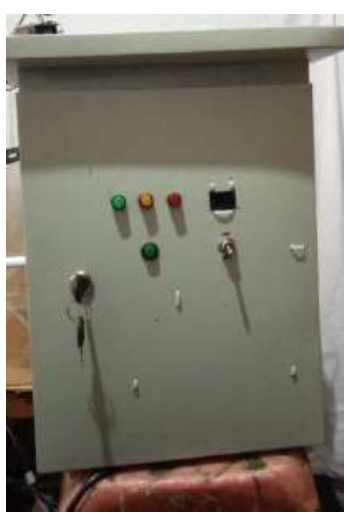

(b)

Gambar 9. (a)Pintu Air (b)Box Panel

Hasil perancangan mekanik terdapat sedikit perubahan dari desain yang sudah dibuat, dimana salah satu sisi yang terpisah oleh pintu air ditinggikan. Mekanik terdiri dari purwarupa bendungan dan box panel. Purwarupa bendungan menggunakan bahan utama akrilik dengan ketebalan $2 \mathrm{~mm}$, dan box panel menggunakana bahan plat besi ketebalan $1 \mathrm{~mm}$, Gambar 8 dan Gambar 9 merupakan hasil perancangan mekanik dari berbagai sisi.

\section{Perancangan dan Realisasi Sistem Elektronik}

Perancangan sistem elektronik terdiri dari pemilihan modul-modul yang digunakan kemudian menggabungkannya dalam diagram pengkabelan. Gambar di bawah merupakan diagram pengkabelan dari modul-modul yang digunakan serta realisasinya. 


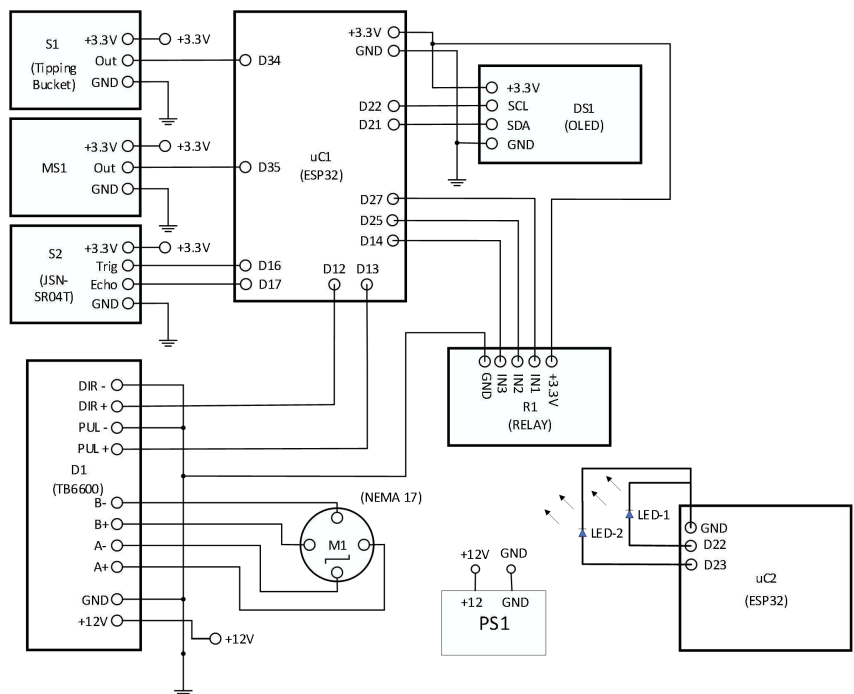

口ambar 10. Diagram Pengakabelan Sistem Elektronika

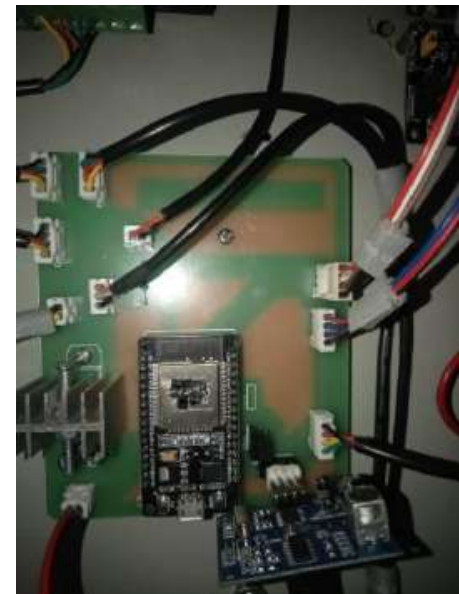

(a)

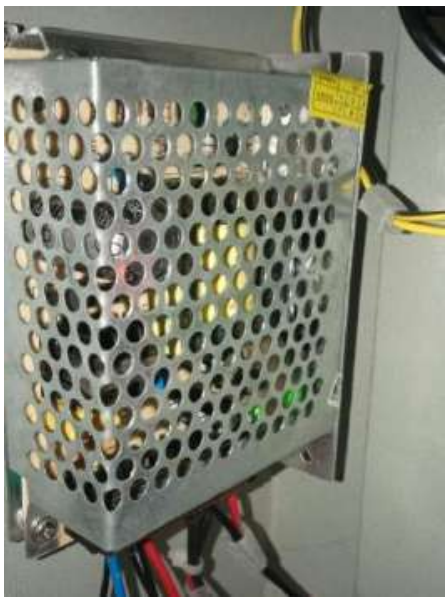

(b)

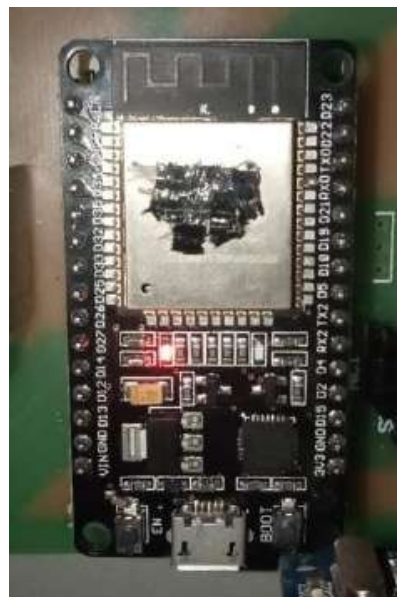

(c)

Gambar 11. (a)Realisasi Keseluruhan(b)Realisasi Sumber Daya(c)Realisasi Modul Mikrokontroler ESP32-

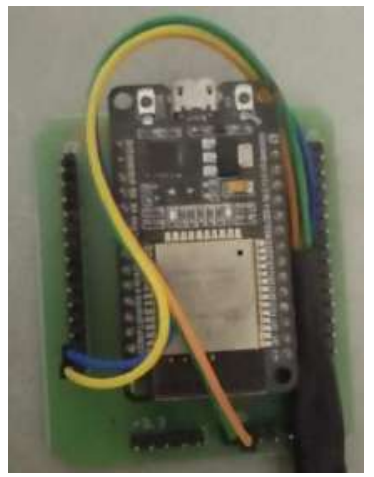

(a)

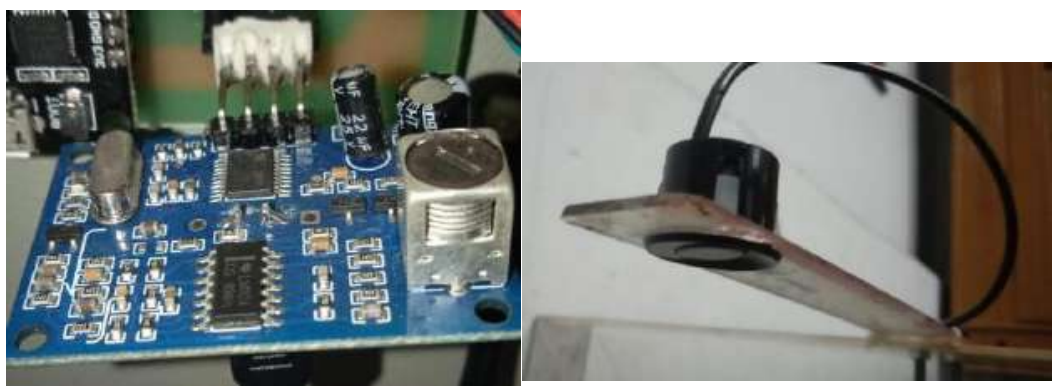

(b)

Gambar 12. (a)Realisasi Modul Mikrokontroler ESP32-2 (b)Realisasi Modul Sensor Ketinggian Air 


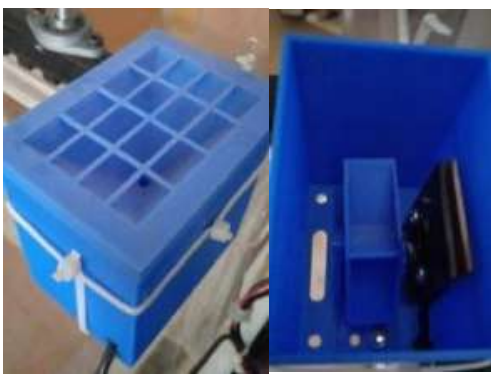

(a)

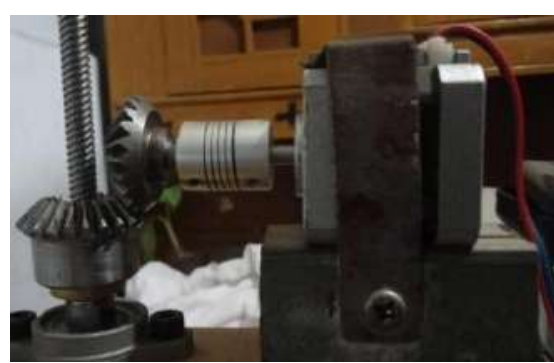

(b)

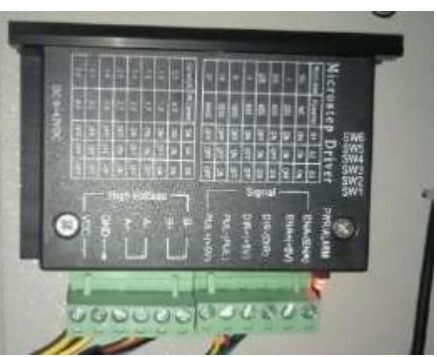

Gambar 13. (a)Realisasi Modul Sensor Curah Hujan (b)Realisasi Modul Motor Stepper

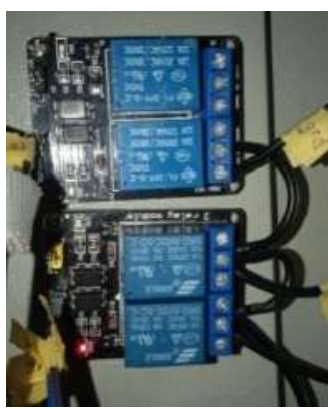

(a)

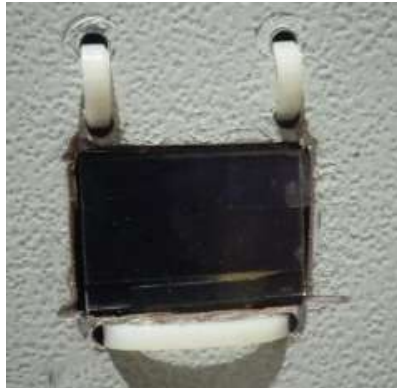

(b)

Gambar 14. (a)Realisasi Modul Relay (b)Realisasi Modul OLED

\section{Perancangan dan Realisasi Perangkat Lunak}

Perancangan perangkat lunak terdiri dari perancangan diagram alir program dan juga perancangan sistem SCADA, yang didalamnya terdiri dari perancangan HMI, Tabel Sequential, dan State Flow Diagram (SFD). Untuk diagram alir program terdiri dari 2 diagram alir yaitu untuk ESP32-1 dan ESP32-2. Diagram alir tersebut akan direalisasikan dengan membuat coding pada software Arduino IDE.

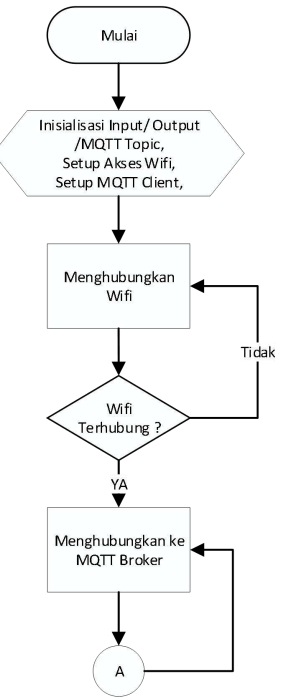

(a)

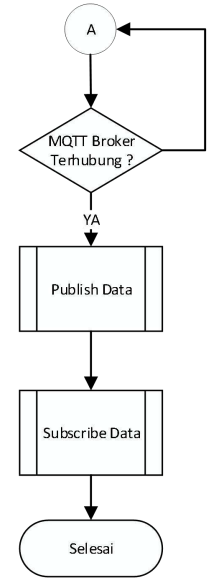

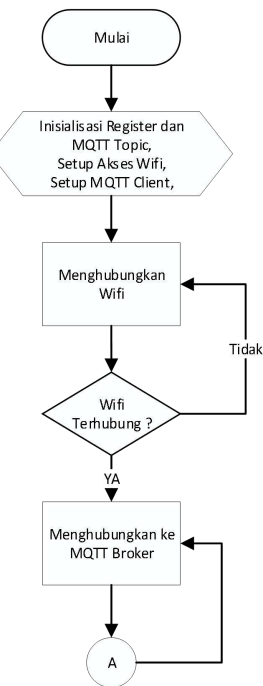

(b)

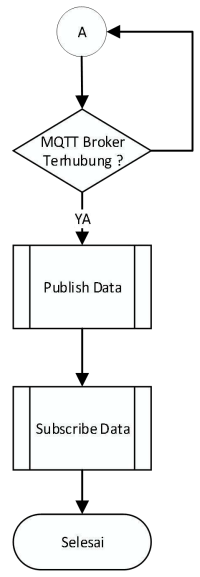

Gambar 15. (a)Diagram Alir Program Utama ESP32-1 (b) Diagram Alir Program Utama ESP32-2

Kedua diagram alir di atas merupakan diagram alir dari program utama pada ESP32-1 dan ESP32-2, dimana ESP32-1 terdapat pada plant dan ESP32-2 terhubung dengan PC sebagai pengirim dan penerima data secara serial ke/dari HMI. Sedangkan untuk perancangan sistem SCADA untuk HMI dibuat menggunakan software Wonderware Intouch. Untuk SFD itu sendiri merupakan aliran proses keadaan dari suatu subsistem atau fungsi dari HMI SCADA. Dari sistem SCADA yang akan dibuat, terdapat 3 pengguna yang dapat mengakses ke sistem, yaitu Administrator, Engineer, dan Operator. 


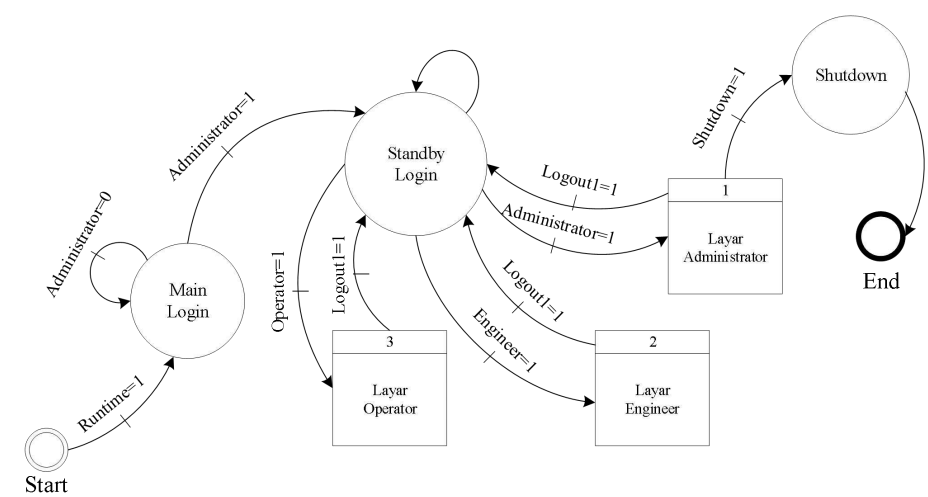

Gambar 16. SFD HMI

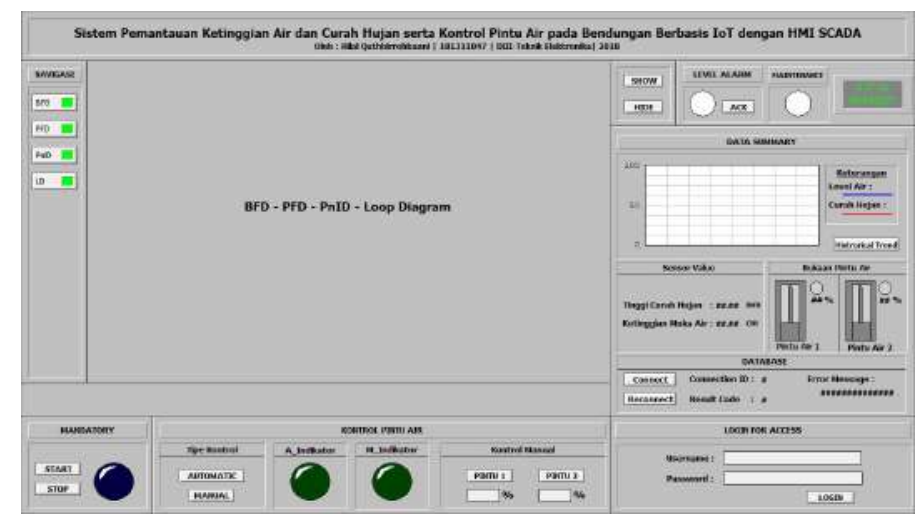

Gambar 17. Desain HMI SCADA

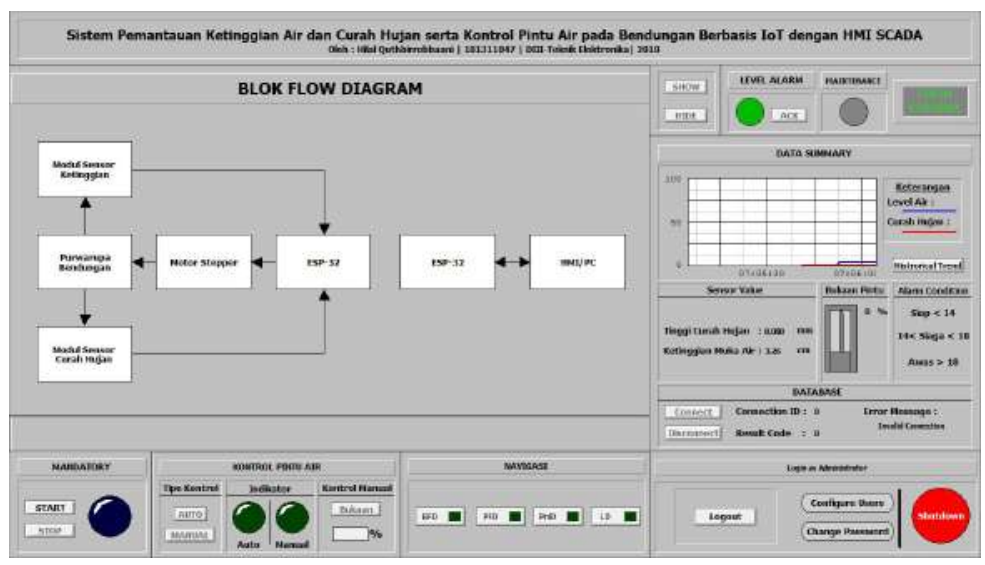

Gambar 18. Realisasi HMI SCADA

Hubungan sebab akibat dari input-output pada HMI SCADA akan dijelaskan pada Tabel Sequential.

Tabel 2. Tabel Sequential

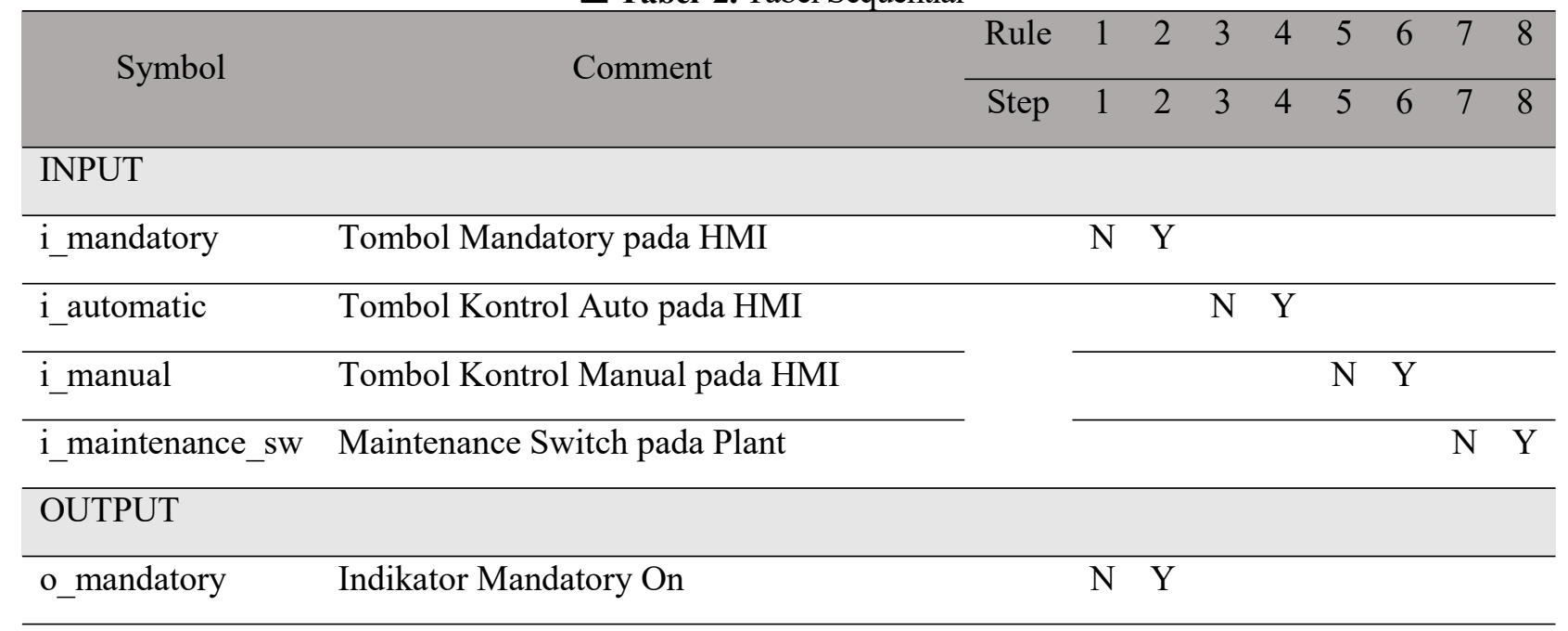


Sistem Pemantauan Ketinggian Air dan Curah Hujan serta Kontrol Pintu Air pada Simulasi Bendungan Besbasis IoT dengan HMI SCSADA

\begin{tabular}{|c|c|c|c|c|c|c|c|c|c|c|}
\hline & Enable Tombol Kontrol Auto pada HMI & & $\mathrm{N}$ & & & & & & & \\
\hline & Enable Tombol Kontrol Manual pada HMI & & $\mathrm{N}$ & Y & & & & & & \\
\hline \multirow[t]{2}{*}{ o_automatic } & Pintu Air Terbuka/ Tertutup Otomatis & & & & $\mathrm{N}$ & $\mathrm{Y}$ & & & & \\
\hline & Disable Tombol Pintu1 dan Pintu2 & & & & $\mathrm{N}$ & $\mathrm{Y}$ & & & & \\
\hline \multirow[t]{2}{*}{ o_manual } & Tombol Pintu1 Enable & & & & & & $\mathrm{N}$ & $\mathrm{Y}$ & & \\
\hline & Tombol Pintu2 Enable & & & & & & $\mathrm{N}$ & $\mathrm{Y}$ & & \\
\hline \multirow[t]{2}{*}{ out_maintenance } & Indikator Maintenance pada HMI On & & & & & & & & $\mathrm{N}$ & $\mathrm{Y}$ \\
\hline & Semua Tombol pada HMI Disable & & & & & & & & $\mathrm{N}$ & $\mathrm{Y}$ \\
\hline \multirow{2}{*}{\multicolumn{2}{|c|}{ Next Step }} & Then & 2 & 3 & 4 & 5 & 6 & 7 & 8 & 1 \\
\hline & & Else & & & & & & & & \\
\hline
\end{tabular}

\section{HASIL DAN PEMBAHASAN}

\section{Pengujian Modul Sensor Ketinggian}

Pengujian modul sensor ketinggian (modul sensor ultrasonic JSN SR04T) ini menggunakan program tanpa library, dan untuk kalibrasi awal sensor menggunakan persamaan berikut, agar dihasilkan pendeteksian dalam bentuk $\mathrm{cm}$.

$$
\text { Jarak }=\left(\frac{\text { Durasi }}{2}\right) * \text { Kecepatan Suara }
$$

Ket :

Jarak $=$ Hasil kalibrasi ke dalam bentuk $\mathrm{cm}$

Kecepatan Suara $=340 \mathrm{~m} / \mathrm{s}(0.034 \mathrm{~cm} / \mathrm{us})$

Durasi = Waktu yang diperlukan gelombang ultrasonik untuk memancar dan diterima kembali (us)

Pembagian durasi oleh "2" dikarenakan waktu yang dihitung adalah waktu untuk memancar dan diterima kembali, sehingga untuk mendapatkan waktu sampai gelombang menyentuh objek yang dituju adalah dengan dibagi "2". Dan agar didapat jarak dalam orde "cm" maka kecepatan suara dikonversi ke dalam bentuk "cm/us", sehingga didapat nilai " $0.034 \mathrm{~cm} /$ us". Setelah dilakukan integrasi dengan mekanik, dikalibrasi kembali untuk mengubah jarak maksimal pendeteksian menjadi nilai awal pendeteksian.

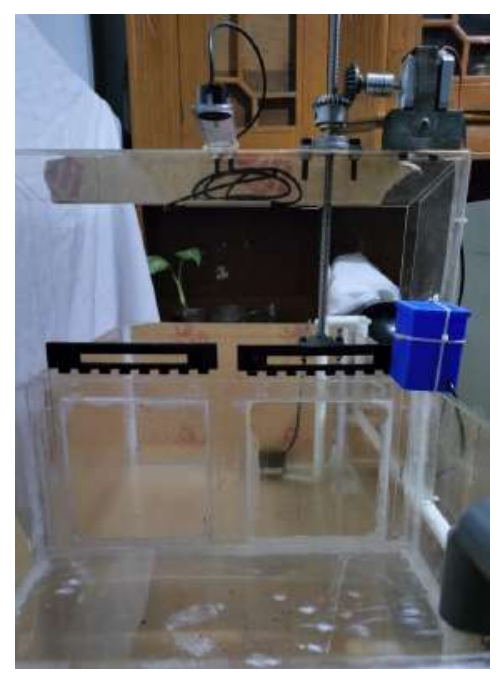

Gambar 19. Posisi Modul Sensor Ketinggian

Posisi ultrasonik berada pada $41.5 \mathrm{~cm}$ dari dasar penampungan air. Dari persamaan 1 dilakukan pengurangan dengan ketinggian posisi modul sensor ketinggian agar dihasilkan posisi $0 \mathrm{~cm}$. 


$$
\text { Ketinggian }=(\operatorname{Jarak}-41,5) *(-1)
$$

Ket :

Ketinggian $=$ Jarak dasar penampungan air dengan posisi ultrasonic Jarak $=$ Pendeteksian sensor dalam orde $\mathrm{cm}$

Persamaan 2 di atas digunakan untuk mendeteksi ketinggian air pada purwarupa bendungan.

- Tabel 3. Hasil Pengujian Modul Sensor Ketinggian

\begin{tabular}{|c|c|c|c|}
\hline No & $\begin{array}{c}\text { Pembacaan Mistar } \\
(\mathbf{c m})\end{array}$ & $\begin{array}{c}\text { Pembacaan Modul Sensor } \\
\text { Ketinggian(cm) }\end{array}$ & $\begin{array}{c}\text { Persentase } \\
\text { Kesalahan (\%) }\end{array}$ \\
\hline 1 & 1 & 1,04 & 4 \\
\hline 2 & 2 & 2,02 & 1 \\
\hline 3 & 3 & 3,07 & 2,33 \\
\hline 4 & 4 & 4,29 & 7,25 \\
\hline 5 & 5 & 5,21 & 4.2 \\
\hline 6 & 6 & 6,12 & 2 \\
\hline 7 & 7 & 7,24 & 3,43 \\
\hline 8 & 8 & 8,32 & 4 \\
\hline 9 & 9 & 9,36 & 4 \\
\hline 10 & 10 & 10,10 & 1 \\
\hline \multicolumn{2}{|c|}{ Rata - Rata Persentase Error } & $\mathbf{3 , 3 2}$ \\
\hline
\end{tabular}

Nilai persentase kesalahan di atas didapat dari persamaan :

$$
e \%=\left(\frac{Y n-X n}{Y n}\right) \times 100 \%
$$

Ket :

$\mathrm{e} \%=$ Persen kesalahan

$\mathrm{Yn}=$ Pembacaan mistar

$\mathrm{Xn}=$ Pembacaan sensor ultrasonic

Untuk mendapatkan pembacaan yang lebih akurat, maka dilakukan kalibrasi dengan mengambil salah satu data dari hasil pengujian di atas, dengan persamaan regresi linear:

$$
y=a x+b .
$$

Ket :

$\mathrm{y}=$ nilai pembacaan mistar

$\mathrm{x}=$ nilai pembacaan sensor ultrasonic

Perhitungan pengkalibrasian :

- Eliminasi untuk mencari nilai a

$$
\begin{aligned}
& 2=a * 2,02+b \\
& 4=a * 4,29+b \\
& \hline-2=-2,27 *(a) \\
& a=\frac{-2}{-2,27}=0,88
\end{aligned}
$$

- Substitusi nilai a ke persamaan agar di dapat nilai $b$

$$
\begin{aligned}
& 4=(0,88)(4,29)+b \\
& b=4-3,41
\end{aligned}
$$




$$
b=0,59
$$

- Hasil pengkalibrasian

$$
y=0,88 x+0,59
$$

Tabel 4. Hasil Pengujian Modul Sensor Ketingian Setelah Kalibrasi

\begin{tabular}{lccc}
\hline No & $\begin{array}{c}\text { Pembacaan Mistar } \\
(\mathrm{cm})\end{array}$ & $\begin{array}{c}\text { Pembacaan Modul } \\
\text { Sensor Ketinggian }(\mathrm{cm})\end{array}$ & $\begin{array}{c}\text { Persentase } \\
\text { Kesalahan }(\%)\end{array}$ \\
\hline 1. & 1 & 1,04 & 4 \\
2. & 2 & 2,02 & 1 \\
3. & 3 & 3,07 & 2,33 \\
4. & 4 & 4,22 & 5,5 \\
5. & 5 & 5,21 & 4,2 \\
6. & 6 & 6,12 & 2 \\
7. & 7 & 7,20 & 2,85 \\
8. & 8 & 8,25 & 3,12 \\
9. & 9 & 9,30 & 3,33 \\
10. & 10 & 10,14 & 1,4 \\
\hline
\end{tabular}
persamaan.

Setelah dilakukan kalibrasi maka persamaan 2 disubstitusikan ke persamaan 5, sehingga didapat

$$
\text { Ketinggian_kal }=(0,88 * \text { Ketinggian })+0,59
$$

Pembacaan modul sensor setelah dikalibrasi memiliki persen error $2.97 \%$, lebih kecil $0.35 \%$, hasil pembacaan modul sensor setelah kalibrasi terdapat pada Tabel 4 Pembacaan modul sensor ketinggian dipengaruhi beberapa faktor eksternal seperti air yang beriak, sehingga hasil pembacaannya fluktuatif atau naik turun.

\section{Pengujian Durasi Pengiriman Data Sensor}

Pengujian durasi pengiriman data sensor dilakukan untuk mengetahui durasi pengiriman data sensor dari plant sampai tertampil di HMI SCADA.

Tabel 5. Hasil Pengujian Durasi Pengiriman Data Sensor

\begin{tabular}{ccccccccccccc}
\hline & \multicolumn{10}{c}{ Percobaan ke-n } & Durasi \\
\cline { 2 - 6 } & $\mathbf{1}$ & $\mathbf{2}$ & $\mathbf{3}$ & $\mathbf{4}$ & $\mathbf{5}$ & $\mathbf{6}$ & $\mathbf{7}$ & $\mathbf{8}$ & $\mathbf{9}$ & $\mathbf{1 0}$ & $\begin{array}{c}\text { Rata- } \\
\text { Rata }\end{array}$ \\
\hline $\begin{array}{c}\text { Durasi } \\
\text { (s) }\end{array}$ & 1,06 & 1,28 & 1,06 & 1,44 & 1,25 & 1,15 & 1,22 & 1,35 & 1,18 & 1,16 & 1,21 \\
\hline
\end{tabular}

Durasi di atas merupakan durasi pengiriman data sensor dari plant sampai tertampil pada HMI SCADA. Durasi pengiriman data sensor dapat dipengaruhi beberapa faktor seperti halnya kualitas jaringan internet dan juga kualitas hubungan ESP32-2 dengan OPC. Pengiriman data yang dilakukan tidak berhenti pada komunikasi lewat internet saja, tetapi juga melalui komunikasi serial antara ESP32-2 dengan OPC untuk menampilkan pada HMI SCADA.

\section{Pengujian Durasi Pengiriman Intruksi Buka/Tutup Pintu Air}

Pengujian durasi pengiriman intruksi buka/tutup pintu air pada plant dilakukan untuk mengetahui durasi dari mulai diberikan intruksi pada HMI SCADA sampai intruksi diterima oleh ESP32-1 dan mendrive motor stepper agar pintu air terbuka/tertutup pada plant. 
__Tabel 6. Hasil Pengujian Durasi Pengiriman Intruksi Buka/Tutup Pintu Air

\begin{tabular}{ccccccccccccc} 
& \multicolumn{11}{c}{ Percobaan ke-n } & Durasi \\
& $\mathbf{1}$ & $\mathbf{2}$ & $\mathbf{3}$ & $\mathbf{4}$ & $\mathbf{5}$ & $\mathbf{6}$ & $\mathbf{7}$ & $\mathbf{8}$ & $\mathbf{9}$ & $\mathbf{1 0}$ & $\begin{array}{c}\text { Rata- } \\
\text { Rata }\end{array}$ \\
\hline $\begin{array}{c}\text { Durasi } \\
\text { (s) }\end{array}$ & 0,97 & 0,66 & 0,98 & 0,87 & 0,82 & 0,69 & 0,75 & 0,91 & 0,95 & 0,81 & 0,84 \\
\hline
\end{tabular}

\section{Pengujian Tingkat Presisi Buka/Tutup Pintu Air}

Pengujian tingkat presisi buka/tutup pintu air bertujuan untuk mengetahui kepresisian pintu air dalam setiap posisi bukaanya.

Tabel 7. Hasil Pengujian Tingkat Presisi Buka/Tutup Pintu Air

\begin{tabular}{cccccc}
$\begin{array}{c}\text { Bukaan } \\
\text { Pintu (\%) }\end{array}$ & \multicolumn{3}{c}{ Percobaan ke-n (cm) } & $\begin{array}{c}\text { Perpindahan } \\
\text { Rata-rata (cm) }\end{array}$ & $\begin{array}{c}\text { Persentase } \\
\text { Error }(\%)\end{array}$ \\
\hline 25 & $\mathbf{1}$ & $\mathbf{2}$ & $\mathbf{3}$ & 1.3 & 0 \\
\hline 50 & 1.3 & 1.3 & 1.3 & 2.8 & 0 \\
\hline 75 & 2.8 & 2.8 & 2.8 & 4.3 & 0 \\
\hline 100 & 4.3 & 4.3 & 4.3 & 5.8 & 0 \\
\hline
\end{tabular}

Dari hasil pengujian di atas didapat persentase error rata-rata sebesar $0 \%$, yang menandakan tingkat presisi buka/tutup pintu air baik.

\section{Pengujian Algoritma Sistem Kontrol Pintu Air Otomatis dan Manual}

Kontrol pintu air otomatis dan manual merupakan mode operasi kontrol pintu air yang terdapat pada penelitian ini. Kontrol pintu air otomatis bekerja dengan memanfaatkan input pembacaan sensor ketinggian air. Pada kontrol pintu air otomatis bekerja berdasarkan ketinggian air pada Tabel 8 .

\begin{tabular}{cc}
\hline Kondisi Alarm & Ketinggian Air (cm) \\
\hline Normal (Siap) & $<10$ \\
\hline Warning (Siaga) & $>10-<13$ \\
\hline Danger (Awas) & $>13$ \\
\hline
\end{tabular}

Bukaan pintu air pada mode otomatis terbagi menjadi 2 bukaan, yaitu bukaan pintu air $50 \%$ dan bukaan pintu air $100 \%$. Bukaan pintu air 50\% tertrigger saat ketinggian air lebih dari $10 \mathrm{~cm}$ dan kurang dari $13 \mathrm{~cm}$. Bukaan pintu air 100\% tertrigger saat ketinggian air lebih dari $13 \mathrm{~cm}$. Pintu akan menutup kembali saat ketinggian air mencapai kurang dari $8 \mathrm{~cm}$.

Untuk mengakses mode kontrol otomatis, pada HMI SCADA harus diaktifkan terlebih dahulu mode otomatisnya. Apabila kontrol otomatis sudah aktif, maka mode kontrol manual tidak berfungsi, sampai ada perintah untuk mengganti mode kontrol.

Pada kontrol manual, buka/tutup pintu air dilakukan oleh operator berdasarkan besaran nilai bukaan yang diberikan. Apabila tidak ada perintah buka/tutup pintu air, maka pintu air akan diam sampai adanya perintah. Untuk mengakses mode kontrol manual, maka pada HMI SCADA harus diaktifkan terlebih dahulu mode kontrol manual.

Tabel 9. Hasil Pengujian Algoritma Kontrol Pintu Air

\begin{tabular}{ccccc}
\hline \multirow{2}{*}{ Mode Kontrol } & \multicolumn{3}{c}{ Ketinggian Air $(\mathrm{cm})$} \\
\cline { 2 - 5 } & Otomatis & Pintu Tertutup & Pintu Terbuka 50\% & Pintu Terbuka $100 \%$ \\
\hline \multirow{2}{*}{ Manual } & Tanpa Perintah & Pintu Tertutup & Pintu Tertutup & Pintu Tertutup \\
\cline { 2 - 5 } & Dengan Perintah & Pintu Tertutup & Pintu Terbuka & Pintu Terbuka \\
\hline
\end{tabular}

Dari Tabel 9 di atas, pada mode kontrol otomatis, pintu air akan membuka dan menutup dengan sendirinya sesuai dengan ketinggian air yang telah ditentukan pada program. Untuk mode kontrol manual apabila tidak ada perintah untuk membuka pintu air, maka pintu air akan tertutup meski alarm sudah dalam mode danger atau awas. Sedangkan apabila diberi perintah untuk membuka pintu air, maka pintu air akan terbuka dengan nilai bukaan sesuai dengan yang diperintahkan dalam range 1-100\%. 


\section{Analisa Sistem Keseluruhan}

Dari hasil pengujian yang dilakukan telah dilakukan 4 pengujian untuk mengetahui kinerja alat. Pengujian mengenai durasi pengiriman data sensor didapat durasi rata-rata sebesar 1,21 detik, dengan data pengujian terdapat pada Tabel IV.6. Dari pengujian mengenai durasi pengiriman intruksi buka/tutup pintu air didapat durasi rata-rata sebesar 0,84 detik, dengan data pengujian terdapat pada Tabel 7.

Pengujian mengenai durasi pengiriman data sensor dan pengiriman intruksi buka/tutup pintu air di atas, dilakukan untuk mengetahui kinerja dari komunikasi yang digunakan, yaitu komunikasi IoT dan juga komunikasi serial. Komunikasi IoT digunakan untuk mengirimkan data antara ESP32-1 dengan ESP32-2. Dan komunikasi serial digunakan untuk mengirimkan data dari ESP32-2 ke OPC, yang selanjutnya ditampilkan pada HMI SCADA. Sehingga, durasi pada kedua pengujian ini tidak hanya delay yang terdapat pada komunikasi IoT nya saja, tetapi ditambah dengan delay komunikasi serial.

Pada pengujian tingkat presisi buka/tutup pintu air didapat persentase kesalahan sebesar $0 \%$, yang menandakan bahwa tingkat presisi buka/tutup pintu air bekerja dengan baik. Data pengujian tingkat presisi buka/tutup pintu air terdapat pada Tabel 8 . Dari persentase error yang didapat, dapat disimpulkan nilai tingkat presisinya sebesar $100 \%$.

Pengujian algoritma sistem kontrol pintu air, dilakukan untuk mengetahui kinerja dari algoritma program yang telah dibuat. Dari kedua mode kontrol yaitu otomatis dan manual memiliki kinerja yang baik, dan hasil pengujiannya terdapat pada Tabel 9. Pengujian algoritma sistem kontrol pintu air dilakukan secara kualitatif.

Dari semua pengujian yang telah dilakukan, terdapat satu masalah dalam pengiriman data sensor. Pengiriman data sensor sedikit terganggu saat pintu air terbuka/tertutup akibat dari program untuk menjalankan motor stepper menimbulkan delay. Setelah dilakukan pengubahan pada program, delay program yang terjadi saat motor stepper bergerak tidak terlihat berdampak pada pengiriman data sensor, tetapi pergerakan motor steppernya menjadi kurang halus. Untuk mengatasi hal tersebut, dapat dilakukan dengan menggunakan 2 modul mikrokontroler yang berbeda untuk pengiriman data sensor dan juga untuk menjalankan motor stepper untuk buka/tutup pintu air.

Untuk sistem keamanan pada alat, belum terdapat sistem bypass untuk menggerakkan pintu air secara manual menggunakan tenaga manusia. Dan juga, belum bisa mengubah mode operasi ke otomatis dengan sendirinya saat koneksi internet terputus.

\section{Kesimpulan}

\section{KESIMPULAN DAN SARAN}

Setelah pembuatan alat pada proyek Tugas Akhir ini selesai, diperoleh kesimpulan sebagai berikut.

1. Simulasi ketinggian air maksimal $15 \mathrm{~cm}$, dengan bukaan pintu air saat terbuka $100 \%$ adalah $5.8 \mathrm{~cm}$.

2. Alat dapat memantau ketinggian air dan curah hujan pada simulasi bendungan secara terusmenerus dari jarak jauh, dengan durasi rata-rata pengiriman data sensor sebesar 1,21 detik.

3. Nilai pembacaan sensor ketinggian air memiliki persen kesalahan rata-rata sebesar $2,97 \%$ dari nilai ketinggian sebenarnya. Dan untuk nilai pembacaan sensor curah hujan sebesar 0,053 inch/trip yang sudah terkalibrasi dari pabrikan dan tidak bisa diubah.

4. Alat dapat mengontrol pintu air pada simulasi bendungan dari jarak jauh secara otomatis maupun manual yang keduanya dioperasikan pada HMI SCADA, dengan durasi rata-rata pengiriman intruksi buka/tutup pintu air sebesar 0,84 detik dan bukaan pintu air memiliki tingkat presisi $100 \%$.

\section{Saran}

Untuk meningkatkan kinerja alat pada proyek Tugas Akhir ini, perlu adanya pengembangan lebih lanjut lagi. Adapun saran untuk pengembangan lebih lanjut adalah sebagai berikut.

1. Penambahan sensor aliran air, agar bertambah parameter untuk bahan perbandingan kondisi bendungan.

2. Penyesuain kembali sensor ketinggian air yang dapat mendeteksi ketinggian air lebih baik lagi, atau pengembangan dari sistem pendeteksian air agar riak yang dihasilkan oleh air tidak terlalu berpengaruh pada pendeteksian ketinggian air. 
3. Penggunaan 2 modul mikrokontroler untuk memisahkan antara pengiriman data sensor dan buka/tutup pintu air oleh motor stepper, agar pengiriman data sensor ataupun buka/tutup pintu air tidak terganggu satu sama lain.

\section{DAFTAR PUSTAKA}

[1] Admindpu, "Mengenal Bangunan Irigasi: Bendung atau Bendungan," 21 Juni 2020. [Online]. Available: https://dpu.kulonprogokab.go.id/detil/246/mengenal-bangunan-irigasi-bendung-ataubendungan. [Diakses 2 Maret 2021].

[2] Anonymous, "Pengertian Bendungan," 16 Februari 2012. [Online]. Available: https://www.ilmutekniksipil.com/bangunan-air/pengertian-bendungan. [Diakses 23 2021].

[3] Anonymous, "Mengenal Sistem SCADA," Juni 2014. [Online]. Available: http://www.infoelektro.com/2014/06/mengenal-sistem-scada.html. [Diakses 2 Maret 2021].

[4] K. A. Indarto, "HMI Scada dan Sistem Pengendalian Logika Fuzzy Pada Simulasi Tiga Pintu Air," Politeknik Negeri Bandung, Bandung, 2018.

[5] M. H. S. Pelaez, "SCADA: A big challenge for information security professionals," 22 Agustus 2010.

[Online].

Available: https://isc.sans.edu/diary/SCADA\%3A+A+big+challenge+for+information+security+profession als/9436. [Diakses 2 Maret 2021].

[6] Y. Yudhanto dan A. Azis, Pengantar Teknologi Internet of Things, Surakarta: UNS Press, 2019.

[7] G. C.Hillar, MQTT Essentials - A Lightweight IoT Protocol, Britania Raya: Packt Publishing, 2017.

[8] R. Andri A, Dasar Implementasi Protokol MQTT Menggunakan Phthon dan NodeMCU, -: Mokosoft Media, 2019.

[9] W. Gastreich, "What is a Stepper Motor and How it Works," Realpars, 9 Juli 2018. [Online]. Available: https://realpars.com/stepper-motor/. [Diakses 2 Maret 2021].

[10] E. Samsul, "Motor Stepper: Prinsip Kerja dan Pengendalian pada Otomasi Industri," Jago Otomasi, 8 April 2019. [Online]. Available: http://jagootomasi.com/motor-stepper-prinsip-kerjadan-pengendalian-pada-otomasi-industri/. [Diakses 2 Maret 2021].

[11] L. Prielipp, "What is a Level Sensor," 17 Juni 2019. [Online]. Available: https://realpars.com/level-sensor/. [Diakses 2 Maret 2021].

[12] Kodrat, "Pengertian dan Cara Kerja Sensor Ultrasonik," 5 September 2019. [Online]. Available: https://www.centipedia.net/pengertian-dan-cara-kerja-sensor-ultrasonik/. [Diakses 19 Agustus 2021]. 